\title{
The use of horizontal social networks to promote and publicize university teaching
}

\author{
E. Lahuerta-Otero*, R. Cordero-Gutiérrez* \\ * University of Salamanca, Department of Business Administration. Campus Miguel de Unamuno, \\ 37007, Salamanca, Spain.
}

\begin{abstract}
The purpose of this paper is to examine the effectiveness of the online advertising techniques through the social network Facebook, as a broadcasting and promotion tool to disseminate information of universities. By means of a case study, we present the findings on a research center belonging to the public sector. Results show that these techniques are able to get a large number of impressions and clicks, which impacts (in terms of awareness and recognition) go beyond the initial targeted group. Although the results are based on a single public teaching center and therefore they cannot be used to make generalizations, the conclusions of the study show the cost-effective effect relationship of these innovative techniques when promoting universities among the online community. Consequently, these methods represent and important supporting point on the universities' marketing strategies when addressing the challenges of this new, digital society.
\end{abstract}

Keywords: Social networks, universities, promotion, advertising, case study, Facebook.

\section{Introduction}

Our society is experiencing an unstoppable development of the information and communication technologies (ICTs). With the rapid digitalization of media, advertising landscape has changed dramatically. Spain accounted for 28.9 million Internet users in 2013 (ONTSI, 2013), 84\% of which consulted the social media very often (ONTSI, 2011). Furthermore, almost 56\% of the Spanish internet users buy on the Internet, which means 15.2 million shoppers spending €816 on average per year (ONTSI, 2013). Consequently, companies invested 874.4 million Euros in digital advertising in Spain in 2013 (IAB Spain, 2014). Online and social advertising accounted for the $21 \%$ of the total share, consolidated its second position only behind a traditional media such as television.

Even if online advertising is becoming more important day by day, it has not replaced the traditional advertising yet, as both techniques are conceived as complementary to each other (Barreto, 2012). This is the reason why several authors point out the need to study the use of the Internet as an advertising tool more in deep (Ailawadi et.al, 2009). The Web 2.0 is understood as a new generation of internet services based on the creation of communities, the network concept and the use of the new ICTs for information dissemination (Musser and O'Reilly, 2006). It includes a set of social media so that users can co-create, organize, edit, share, comment and evaluate content by forming social networks that interact with each other.

This research will focus on horizontal social networks, which are those formed by users with no particular interest or objective on a particular topic (ONTSI, 2011). Individuals participating in these types of networks are looking for entertainment and communication, so they become a powerful tool to gain and build customer loyalty from a business perspective (Cordero-Gutiérrez and Santos-Requejo, 2014).

Businesses can no longer afford to ignore the benefits of using social media. In the past, customers consulted with a limited number of family members of friends before making a purchase. The frequent use of social media increases that number to thou- sands of opinions from all over the world on a single click. This means that 2.0 services rely on 
a disintermediation process (Criado-Grande, 2012) that makes customers and businesses engage in a closer relationship. When customers are involved in the purchasing process, they feel valued and they generate a positive feedback that spreads instantly at no cost. Cost reduction and greater participation and customer involvement makes from online advertising no longer a luxury; but an affordable necessity. Recent studies found that social media marketing techniques can generate more business exposure, increased traffic and improved search engine rankings (Stelzner, 2011). Even if the media landscape has dramatically changed, and investments in digital advertising increase every year, is not yet well understood how firms can use this forms of publicity and their impacts on organizational goals (Stephen and Galak, 2010). Today's consumers expect companies to have an online presence in social media and it is not just another channel for disseminating corporate information. It represents a tremendous opportunity to engage and create social bonds with customers and followers, with helps to improve corporate reputation (Nair, 2011).

To help filling this literature gap, this study presents an empirical case study to test the effectiveness of the online advertising techniques in horizontal social networks.

\section{Theoretical framework}

According to Barreto (2012), social network sites have three main functions: personal, social and infomercial. First, social network are build based on public profiles build by users that enter the network to express themselves, make comments, and share contents that become public. Secondly, social networks have an undeniable social aspect as they act as spaces where users can find other people with similar interests and share opinions, and all kinds of content (text, images, audio, and video). This imply that shared content has a wider diffusion thanks to the social network sites. Finally, social network sites are an excellent platform to broadcast information in which companies interact as the Internet allows for a direct and dynamic contact between firms and users or customers. Firms use social networks in order to promote their services, increase brand awareness, and understand shoppers better or get them involved in the co-creation of content. This implies a double informational and commercial interest (infomercial) by companies when using social networks.

Regarding the use of social networks in teaching environments, it is clear that universities need a consolidated social presence as their "customers": students, teachers, researchers, administrative staff... are in direct and daily contact with these platforms. By creating these profiles in horizontal social networks like Facebook, teaching centers can integrate the diverse community members together in an informal and participative environment that favors a better service quality. Besides detecting and solving problems, this channel acts as an excellent promotion means for prospective students, as $97.7 \%$ of the young Spaniards who are about to start university studies are present at one or more social networks (eTítulo, 2013). Accordingly, Facebook it the horizontal social network present at most Spanish universities with 8,413 followers on average (eTítulo, 2013) of which 58\% are students. The University of Salamanca is situated in the sixth place of the national ranking (Avanzaentucarrera.com, 2013) with 45,482 followers on their official Facebook profile. Most of these social pages interact with users by answering questions and comments from students, which favors interaction and increases the diffusion of contents. Most universities post several times a day, so their profiles are also up to date (eTítulo, 2013). 
Companies and organizations are aware of the power of advertising in the online world, as it is capable of adapt the content according to the rapid technological changes and, besides it implies a direct contact with the prospective customers. Companies have now a unique opportunity to connect with their customers by offering unique, adapted and personalized promotions using the social network sites (Ailawadi et al., 2009). This also means that online advertising has suffered from severe criticisms, as some users consider it to be deceitful, mean, abusive and annoying (Forrester Research, 2006). Bearing in mind the fact that these social networks may not be the ideal place to show annoying and intrusive advertisements, the platforms have redesigned their strategies so they can generate customer trust by using the power of social networks and the effects they have in the contact list of the users. If publicists progressively incorporate social elements to advertisement, it is easier for users to accept, cooperate and transmit the message. Moreover, peer and social pressure can turn users' attitudes, values or behaviors in regard of a company, brand or service so they conform to the group norms. This will ultimately increase potential customers (Barreto, 2012).

Following this theory, users become fans of a Facebook page, so they get the latest updates of the organization on their walls, and they can keep up with the latest promotions, latest arrivals, contests or relevant information. When users see this type of content they can indicate they like it using the "like button" and they can also share it. This makes information spread so it can reach other users that belonging to the fans' network. In this manner, a single user transmits broadcasts and expands the information generated in origin by a company. This is one of the reason several authors describe the remarkable characteristics (in terms of efficiency with a relative low cost) of the social networks as a way to distribute online advertising (Neff, 2009).

Authors such Harris and Rae (2009), point out that this social benefits can also extend to SMEs as brand awareness increases exponentially at a minimum cost. Furthermore, as Facebook allows for a complete personalization and segmentation of the targeted population in the campaign, unnecessary costs can be avoided (Anon, 2011). The positive impacts of an advertising campaign are also capable of improving the natural positioning (SEO) of a webpage (Lahuerta-Otero, Muñoz-Gallego and Pratt, 2014). Therefore, when businesses create public social profiles and interact successfully with their fans, the search engines improve the position of those websites the publications are mentioning. In this way, when a user is looking on the Internet for information related with these companies, their results will rank organically (without conducting a SEM paid advertising campaign) on the first positions of the search engine.

Companies using social media proclaim they are receiving measurable business benefits including increased sales and market size, improved customer satisfaction and relationships, improved employee relationships, better and faster technical support, reduced marketing expenses and improved search engine rankings (e.g., Angel and Sexsmith 2011; Askook and Nakata, 2011; Stelzner 2011).

\section{Methods}

This research will use the case study method to analyze the results obtained by a research group of the University of Salamanca (Spain) using Facebook ads campaigns. We will focus on the teaching part, as the case study method has been used before in similar environments (Roa, 2013; Chan 2011 and 2012). This group is dedicated to teaching in the new technologies area. They regularly conduct online and offline 
courses, seminars and conferences and they also have official masters and degrees. Their presence on social networks started back in 2012 when they created public profiles in horizontal social networks such as Twitter, Facebook, LinkedIn and Google + .

We chose to conduct an advertising campaign through Facebook as it is a simple, effective and economic way to promote teaching with a potential reach of 1.35 billion users worldwide. Facebook is the main global social network accounting for the 23.39\% of the worldwide traffic, and it is the main social network in Spain (Shareaholic, 2014). With 13.5 billion users and 864 million daily active users, this networks gets 1.8 million likes per minute and shares 41,000 publications every second (Qmee, 2013). Users mainly join this social network to look for friends, to get social support, to entertain themselves, to look for information and also due to its convenience. Consequently, we may say that users spend time on Facebook in search for social capital (Pikas and Sorrentino, 2014).

\section{Results and Discussion}

As observed in table 2, the case study presents extremely positive results. This center increases their fans number and publication's reach significantly. The description of the most important metrics and KPIs (key performance indicators) of the campaigns are described below:

- Reach: The number of people the ad was served to. The number of people reached is really high as with only 670 fans we got 417,000 people reached This means there is a chance to increase the contacts with other Facebook members in 4 persons for every fan in case 1, and of 662 persons for each fan.

- Impressions. The number of times the ad was served. We need to bear in mind that a high impression rate is necessary, as firms are never alone when advertising at a users' wall. This is the reason why in order to get a higher reach levels we see a 3-5 times frequency (on average) per every individual that sees the ad.

- Cost per 1,000 impressions (CMP). The average cost the firm pays to have 1,000 impressions on its ad. This cost will depend on the number of ads with similar segmentation criteria competing to appear on a users' wall. In this case, we can see that when competing with similar ads, the cost of publication (although economic) is bigger than in other similar Facebook campaigns. This may be because these ads have more general content and also stronger competence in this social network. The degree of engagement of the fans with the firm is also an important factor.

- Clicks. The number of total clicks the ad gets. We can observe that in both cases the number of clicks is remarkable, reaching 8,376 clicks. These results can be obtained thanks to a good strategic planning and content of the ad, as well as its attractiveness for the targeted users.

- Unique total clicks. The total number of unique people who have clicked on the ad. This is a very important metric as it allows us to know if our advertisements get several clicks from the same user. This means our ad is catching users' attention so they repeat the action to get informed on the proposed offer (26.83\%). This fact increases the chances that an individual will enroll on some of the teaching courses or seminars advertised. We can also observed that there is a significant different between clicks and unique clicks in both case studies, but the results are consistent as the landing website 
contains all information related to masters, $\mathrm{PhD}$ or courses offered by this research center.

- Click-Through Rate (CTR). The number of clicks the ad gets, divided by the number of impressions. This metric indicates the effectiveness of the publicity. In this case we can see that ads get an important number of clicks related with impressions (CTR = 0.47). This means that the ads on this case study is related with high-demand teaching areas, so the potential students are willing to show an interest on the ads.

- Cost per click (CPC). The average cost per click for these ads, calculated as the amount spent divided by the number of clicks received. As shown in table 1, the cost for clicks when the objective is to get website clicks is lower (3 times less on average). This result is logical as when users click on the like button, they show a big commitment with the page. They will get the latest news and updates about the research centers and some individuals do not want this kind of information to appear on their Facebook wall. Nevertheless, the relative cost of Facebook ads campaigns is lower compared to other type of similar platforms where the CPC can be 15 or more times higher (e.g. Google Adwords).

- Actions: the number of actions taken on the page, page app or event after the ad was served to someone, even if they did not click on it. Actions include page likes, comments, shares, app installs, conversions, event responses and more. Results show that the center got the most actions when getting website clicks. Raisons may be the won content of the ad, and also the great amount of information an individual gets by visiting the landing page. However, the ads created to increase the number of "likes" got worse results, as explained above.

- Money spent: total money spent on a particular campaign. The cost of the different ad sets was below the established budget for both case studies, as campaigns were redefined to adjust budget depending on the ads' needs (more money was spend on the website clicks campaign than on the "likes" one).

Table 1. KPI of the different Facebook campaigns on the case study.

\begin{tabular}{|c|c|c|}
\hline & \multicolumn{2}{|c|}{ Results } \\
\hline Initial campaign date & $08 / 09 / 2014$ & $31 / 07 / 2014$ \\
\hline End campaign date & $01 / 11 / 2014$ & $30 / 10 / 2014$ \\
\hline Objective & Website clicks & Page likes \\
\hline Reach & 416.979 & 8.429 \\
\hline Frequency & 4,263423 & 3,210108 \\
\hline Impressions & 1.777 .758 & 27.058 \\
\hline CPM (Euros) & 0,30224 & 0,845591 \\
\hline Clicks & 8.376 & 126 \\
\hline Total unique clicks & 6.604 & 122 \\
\hline Click-through rate (CTR) & 0,471155 & 0,465666 \\
\hline CPC (Euros) & 0,064149 & 0,181587 \\
\hline Actions & 6.789 & 52 \\
\hline Total spent (Euros) & 537,31 & 22,88 \\
\hline
\end{tabular}




\section{Conclusions}

In the light of the results obtained by the two case studies, this research shows the efficacy of advertising in horizontal social networks to promote teaching-related content. The success of both campaigns was bigger than expected, thanks to the improvement of the attention and awareness from Facebook users to the organizations. However, we need to point out that impressions or clicks do not necessary mean attitudes or future students' behaviors, as we did not measure conversions in this research.

As our results show, a well-structured and oriented campaign may have a significant reach. This makes these social platforms a valuable tool to sell and promote universities. However, we need to highlight that in order to reach its potential, advertising campaigns need to act on Facebook pages with a sufficient number of users. This also means that Facebook pages content must be updated, relevant and carefully designed so universities and faculties can create an own social brand among users (Chan, 2011).

It should be noted that faculties or research centers dependent on public universities do not have a large advertising budget. Our study reveals that the use of paid advertising in horizontal social networks can become an effective communication solution without wasting resources away. The effort in terms of time, resources and money is relatively small compared to the good results obtained. This is the reason why we can affirm that horizontal social networks are a good communication platform for organizations involved in teaching, which can increase the ratio of enrolled students in the different activities promoted such as courses, research seminars, degrees or conferences.

Thanks to the big development of the advertising tools in the social networks (especially in Facebook and Twitter), there is greater flexibility to launch diverse campaigns adapted to a segmented targeted population. These characteristics allow for further promotion and diffusion possibilities among potential users, which would be difficult to reach using traditional media.

In this line, the new 2.0 advertising techniques, more precisely the use of the Facebook Ads tool, allows for the creation of fully personalized and segmented publications, adapted to the target university's need in every one of the ad sets. Accordingly, social network sites become a powerful and original information and promotion tool that channels and understands the needs of their users' community (which differ depending on the role of the user: follower, student, teacher, prospective student, administrative staff...) and meets them in a personalized and specific manner.

These advertising techniques are cost-efficient and innovative, and so they become an excellent attraction tool for prospective students. Consequently, we strongly recommend that both public and private universities, aware of this new technological change, adapt their communication strategies so they include active social profiles in the most relevant horizontal social network sites: Facebook, Twitter, LinkedIn, Google + or even Instagram.

\section{Limitations and further research lines}

The present research suffers from several limitations that we intend to improve with future studies. First, even if the quantitative results seem to indicate the campaign's success, we cannot prove the real impact of the advertising on users. Future research 
should collect the opinion of the recipients of advertising in order to prove their real effectiveness. Moreover, we cannot deny that many social network users are reluctant to advertising, so the ignore the ads they are exposed to. Consequently, this variable should be taken into account in future studies to measure the advertising effectiveness more precisely. Furthermore, this case study belongs to a teaching center with already consolidated social profiles located in the same city of a single country, so future studies should enlarge the sample to study the effects of these campaigns in different contexts. It would also be relevant to collect data on other, alternative campaigns available on Facebook, as well as the effect that, within the same campaign, different ads have on the targeted public in order to determine the most effective attraction factors (content, image, design, ad placement...). Due to the fact that the number of social network users grows every day, it is logical to think that future research will aim to determine the most effective variables to include in this new, innovative online advertising techniques.

\section{References}

Ailawadi, K.L.; Beauchamp, J.P.; Donthu, N.; Gauri, D.K. \& Shankar, V. (2009). Communication and promotion decisions in retailing: A review and directions for future research, Journal of Retailing, 85(1), 42-55.

Angel, R., \& Sexsmith, J. (2011). Social Networking: The Corporate Value Proposition. Available at: http://iveybusinessjournal.com/topics/leadership/social-networkingthe-corporate-value-proposition\#.VL90JUeG840

Anon. (2011). Friends in online places, Strategic Direction, 27(10), 19-22.

Askool, S., \& Nakata, K. (2011). A conceptual model for acceptance of social CRM systems based on a scoping study. AI and Society, 26(3): 205-220.

Avanzaentucarrera.com. (2013). Las universidades en las redes sociales, available at: http://www.avanzaentucarrera.com/llegaraser/especiales/especial-carreras/lasuniversidades-en-las-redes-sociales/

Barreto, A.M. (2012). Do users look at banner ads on Facebook?, Journal of Research in Interactive Marketing, 7(2), 119-139.

Chan, C. (2011). Using online advertising to increase the impact of a library Facebook page, Library Management, 32(4/5), 351-370.

Chan, C. (2012). Marketing the academic library with online social network advertising, Library Management, 22(8/9), 479-489.

Cordero-Gutiérrez, R. \& Santos-Requejo, L. (2014). La confianza y la actitud hacia la red social como determinantes de aceptar herramientas de marketing. Diferencias según intensidad de uso de la red, DOCFRADIS, Colección de documentos de trabajo Cátedra Fundación Ramón Areces de Distribución Comercial, DOC 03/2014

Criado-Grande, I. (2012). Redes sociales y open government. Hacia unas administraciones locales en red y abiertas, Revista Democracia y Gobierno Local, 18/19, 5-12.

eTítulo. (2013). Informe eTítulo 2013, desarrollo e influencia de las TICs en la universidad española, available at: https://www.signe.es/sites/www.signe.es/files/eTitulo\%20informe\%20TIC2013.p df 
Forrester Research (2006). Consumers love to hate advertising”, Forrester Research, Cambridge, MA.

Harris, L. \& Rae, A. (2009). Social networks: the future of marketing for small business, The Journal of Business Strategy, 30(5), 24-31.

IAB Spain (2014). La publicidad digital aumenta su peso en el reparto de la inversión publicitaria, available at: http://www.iabspain.net/noticias/la-publicidad-digitalaumenta-su-peso-en-el-reparto-de-la-inversion-publicitaria/.

Lahuerta-Otero, E., Muñoz-Gallego, P.A \& Pratt, R. (2014). Click-and-mortar SMEs: Attracting customers to your website?, Business Horizons, 57(6), 729-736.

Musser, J \& O’Reilly T. (2006). Web 2.0 principles and best practices, O’Reilly Radar, ISBN-0-596-52769-1.

Nair, M. (2011). Understanding and measuring the value of social media. The Journal of Corporate accounting \& Finance, 22(3) 45-51.

Neff, J. (2009). Study: ROI may be measurable in Facebook, MySpace after all, Advertising Age, 80(12), 1.

ONTSI. (2011). Las Redes Sociales en Internet, available at: http://www.ontsi.red.es/ontsi/es/estudios-informes/estudio-sobre-elconocimiento-y-uso-de-las-redes-sociales-en-espa\%C3\%B1

ONTSI. (2013). Perfil sociodemográfico del internauta, análisis de datos INE 2013, available http://www.ontsi.red.es/ontsi/sites/default/files/perfil_sociodemografico_de_los_i nternautas_2013_0.pdf

Pikas, B. \& Sorrentino, G. (2014). The effectiveness of online advertising: consumer's perception of ads on Facebook, Twitter and YouTube, Journal of Applied Business and Economics, 16(4), 70-81.

Qmee (2013). What happens online in 60 seconds, available at http://blog.qmee.com/qmee-online-in-60- seconds/

Roa, J.M (2013). Las redes sociales, una potente herramienta al servicio del Open Government, Las redes sociales digitales en la gestión y las políticas públicas. Barcelona: Escola d’Administració Pública de Catalunya.

Shareaholic. (2014). Facebook and Pinterest are the King and Queen of Social Referralls, available at: https://blog.shareaholic.com/social-media-traffic-trends04-2014/

Stelzner, M. A. (2011). 2011 Social Media Marketing Industry Report: How Marketers Are Using Social Media to Grow Their Businesses. Available at: http://www.socialmediaexaminer.com/social-.

Stephen, A. T \& Galak, J. (2010). The complementary roles of traditional and social media publicity in driving marketing performance, Faculty and Research working paper, INSEAD, 2-40. 